\title{
La question du pauvre dans le premier psautier davidique, Psaumes 3-41, comme réponse à Proverbes 30,13-14
}

\author{
BERNARD GOSSE (ANTONY, FranCE)
}

\begin{abstract}
Le premier psautier davidique correspond à une réaffirmation du Messie davidique et par la même occasion celle du Pauvre postexilique exploité auquel David est identifié par les titres des psaumes. La prise en compte du Pauvre est conforme à l'influence du livre des Proverbes et plus spécialement Proverbes 30,1-14 sur le premier livre du Psautier. La référence à l'Arche de Yahvé que David a fait monter à Jérusalem explique le rôle du Psaume 68 dans le premier livre du Psautier et audelà celle du livre des Nombres.
\end{abstract}

The first Book of the Davidic Psalms corresponds to a reaffirmation of the Davidic Messiah. Similarly, they correspond to exploitation of the postexilic poor in which David is identified in the titles of the psalms. By taking into account the poor in the first book of the Psalter, the first book reveals the influence of the Book of Proverbs, especially Prov 30,1-14. The reference to the Ark of Yahweh that David moved to Jerusalem, explains the role Psalm 68 played in the first book of the Psalms as well as in the Book of Numbers.

KEYWORDS: Ark (of Yahweh), David, humble, poor, messiah, messianic, Proverbs 30:1-14, Psalm 3-41, Psalm 18, Psalm 68, Psalms of David.

\section{A INTRODUCTION}

Lors du SBL de Berlin en Août 2017, j'ai présenté une contribution, sur les évolutions institutionnelles du retour de l'exil, «David and Moses», ${ }^{1}$ corrigée par Phil Botha. Lors du même congrès, Phil Botha a suggéré l'importance du pauvre marginal, au retour de l'exil, dans le cadre du premier psautier davidique, Ps 341, particulièrement le Ps $4 .{ }^{2} C^{\prime}$ 'est à la suite de cette rencontre, qu'il m'est

* Article submitted: 2019/03/04; peer reviewed: 2019/07/08; accepted: 2019/07/16. Bernard Gosse, "La question du pauvre dans le premier psautier davidique, Psaumes 341, comme réponse à Proverbes 30,13-14," OTE 32 no. 2 (2019): 544-555. DOI: https://doi.org/10.17159/2312-3621/2019/v32n2a15.

1 Bernard Gosse, «David and Moses», in Innovation in Persian Period Judah: Royal and Temple Ideology in its Near Eastern Setting (FAT II; eds. Christine Mitchell and Katherine E. Smith; Tübingen: Mohr Siebeck, 2019), forthcoming.

2 Sur la question du pauvre dans le premier psautier davidique, voir Johannes Bremer, «Eine „Armenredaktion“ im 1. Davidpsalter? Impulse vor dem Hintergrund 
apparu que la réaffirmation messianique davidique du premier psautier davidique, ${ }^{3}$ devait également être celle du pauvre. ${ }^{4}$

\section{B LE PSAUME 1 COMME INTRODUCTION AU PSAUTIER, L'INFLUENCE DU LIVRE DES PROVERBES SUR LE PSAUTIER, PROVERBES 30,1-14, LE PREMIER PSAUTIER DAVIDIQUE ET LA QUESTION DU PAUVRE}

Les Ps 1-2 servent d'introduction, à l'ensemble du Psautier, et donc également aux Ps 3-41..$^{5}$ Le Ps 1, définit une opposition entre les justes, צדיקים (Ps 1,5.6) et les impies, רשעים (1,1.4.5.6), le juste étant d'abord présenté comme celui qui ne suit pas l'exemple des impies, des pécheurs et des railleurs (Ps 1,1). Dans le cadre du premier psautier davidique, Ps 3-41, 1'opposition, רשע / צדיק, est reprise en : Ps 7,$10 ; 11,5 ; 31,18-19 ; 32,10-11 ; 34,22$; et particulièrement en 37,12.16.17.21.28-29.32.39-40; avec צדיק: Ps 1,5.6; 5,13; 7,10.12; 11,3.5.7; 14,$5 ; 31,19 ; 32,11 ; 33,1 ; 34,16.20 .22 ; 37,12.16 .17 .21 .25 .29 .30 .32 .39$ et רשע: Ps 1,1.4.5.6; 3,8; 7,10; 9,6.17.18; 10,2.3.4.13.15; 11,2.5.6; 12,9; 17,9.13; 26,5; 28,3; 31,$18 ; 32,10 ; 34,22 ; 36,2.12 ; 37,10.12 .14 .16 .17 .20 .21 .28 .32 .34 .35 .38 .40 ; 39,2$. La question est de savoir si l'opposition «juste» / «impie», est équivalente à l'opposition «pauvre» / «riche», dans les Ps 3-41. Or le Psautier connâ̂t l'influence du livre des Proverbes, dès Ps 1,1. «Heureux (אשרי) l'homme qui ne suit pas le conseil des impies (רשעים), ni dans la voie (ובדרך) des pécheurs (חטאים) ne s'arrête, ni au siège des railleurs (לצים) ne s'assied», en réponse à Pr 1,22: «Jusques à quand, ô niais (פתים), aimerez-vous la niaiserie (פתים)? Et les railleurs (ולצים) se plairont-ils à la raillerie (לצון)? Et les sots haïront-ils le savoir?». Ps 1,1 reprend les conseils de Pr 1,10: «Mon fils, si des pécheurs (חטאים) veulent te

sozio-ökonomischer Entwicklungen», in Trägerkreise in den Psalmen (BBB 178; eds. Frank-Lothar Hossfeld, Johannes Bremer and Till Magnus Steiner; Bonn: University Press / Göttingen: V\&R Unipress, 2017), 181-205. La question du pauvre était déjà une préoccupation de Phil Botha dans d'autres parties du Psautier. Phil J. Botha, «"The honour of the righteous will be restored": Psalm 75 in its social context», OTE 15 (2002): 320-334.

3 Bernard Gosse, L'espérance messianique davidique et la structuration du Psautier (Pendé: Gabalda, 2015).

4 Bernard Gosse, «La réaffirmation messianique du Ps 18 dans la perspective du salut du marginal au retour de l'exil», ZAW 130 (2018): 586-601.

5 Hans-Johachim Kraus, Psalms 1-59: A Commentary (CC; trans. Hilton C. Oswald; Minneapolis, MN: Augsburg, 1988), 122: «But, finally, we must not forget that Psalm 1 is the preamble of the Psalter». Le Ps 1 débute par אשרי האיש. Jean-Luc Vesco, Le Psautier de David traduit et commenté I (LD 210; Paris: Cerf, 2006), 56, remarque qu'une bénédiction conclut les cinq livres du Psautier, Ps 41,2; 72,17; 89,16; 106,3; 144,15. La bénédiction de Ps 41,2 concerne les pauvres, même si c'est avec un vocabulaire inhabituel dans le premier livre du Psautier: «Heureux (אשרי) qui pense au pauvre (דל) : au jour de malheur, Yahvé le délivre». Une bénédiction אשרי, conclut également l'introduction du Psautier en Ps 2,11. 
séduire (יפתוך), ${ }^{6}$ n'y va pas !», et Pr 4,14: «Ne suis pas le sentier des impies (רשעים), ne t'avance pas sur la voie (בדרך) des mauvais», d'où la possibilité de la bénédiction de Pr 3,13a: «Heureux (אשריר) l'homme qui a trouvé la sagesse».

Dans le cadre de l'influence du livre des Proverbes sur le Psautier, Pr 30,1-14 joue un rôle important. ${ }^{7}$ Dans ce cas l'opposition puissants / pauvres est claire avec en Pr 30,13-14: «13 engeance aux regards (עיניו) altiers et aux paupières hautaines, 14 engeance dont les dents sont des épées, les mâchoires des couteaux, pour dévorer les pauvres (עניים) et les retrancher du pays, et les malheureux (ואביונים), d'entre les hommes».

Phil Botha avait déjà traité de la question du pauvre dans le premier psautier davidique dans son article «Pride and the Suffering of the Poor in the Persian Period: Psalm 12 in its Post-Exilic Context». ${ }^{9}$ Il se référait à mon article «L'influence de Proverbes 30,1-14 sur les cantiques bibliques, à travers le Psautier». ${ }^{10} \mathrm{Je}$ soulignais l'influence de $\operatorname{Pr} 30,1-14$ sur le Ps 12. Le caractère éprouvé des paroles divines mentionnées en Ps 12,7: «Les Paroles (אמרות) de Yahvé sont des paroles (צמרות) sincères, argent natif (צרוף) qui sort de terre, sept fois épuré», correspond à Pr 30,5: «Toute parole (אמרת) (מרות) ${ }^{11}$ de Dieu est éprouvée (צרופה), il est un bouclier pour qui s'abrite en lui». La dénonciation de l'exploitation sociale mentionnée en Pr 30,14, est pour sa part reprise en Ps 12,6: «A cause des pauvres (עניים) qu'on dépouille, des malheureux (אביונים) qui gémissent, maintenant je me dresse, déclare Yahvé: j'assurerai le salut à ceux qui y aspirent». La «corruption» est encore mentionnée en Ps 12,9. Dans le premier livre du Psautier, cette injustice sociale est étroitement liée à l'impiété. L'expression araméenne de Pr 30,1: לא יתי אל לא יתי אל = «il n'y a pas de Dieu, il n'y a pas de Dieu», trouve son équivalent en hébreu en Ps 10,4: אין אלהים. L'influence du livre des Proverbes et particulièrement Pr 30,1-14, sur le Psautier, joue donc un rôle rédactionnel quant à la prise en compte de la question du pauvre marginal au retour de l'exil.

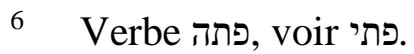

7 Bernard Gosse, L'influence du livre des Proverbes sur les rédactions bibliques à l'époque Perse (ST 14; Paris: Gabalda, 2008), 311 (Index sur Pr 30,1-14).

8 Voir l'anagramme entre עניי (ם) עי (ו עי (ו) En fait, il suffit de faire passer le premier ' de עיני après la 3.

9 OTE 25 (2012): 40-56.

10 ZAW 119 (2007): 528-538. Le titre de l'article ne met pas en valeur le rôle de Pr 30,1-14 dans le Psautier, et donc la question du pauvre. Mais les liens avec les cantiques de 2 S 22 et 1 S 2,1-10, vont dans le sens de l'identification de David avec le pauvre, et permet même de comprendre le prolongement en Luc 1,46-56. Je continuais par la prise en compte des relations avec Ex 15 et Dt 32.

11 אמרה : terme rare. Les références dans le Psautier et même ailleurs doivent faire partie de l'influence du livre des Proverbes dans les rédactions bibliques.
} 


\section{LA RÉAFFIRMATION MESSIANIQUE DAVIDIQUE DANS LE PSAUTIER, LE PSAUME 18, PROVERBES 30,1-14 ET LE PREMIER PSAUTIER DAVIDIQUE}

Le Ps 2, présente, pour sa part, le Messie en opposition aux rois de la terre. Dans les Ps 3-41, en parallèle de l'opposition juste impie, une lecture davidique a été également proposée, à travers les titres des psaumes. ${ }^{12}$ Cette lecture identifie David, au pauvre du retour de l'exil. En conséquence la réaffirmation messianique davidique du Ps 18, concerne également le pauvre marginal du retour de l'exil. Dans mon livre sur la structuration du Psautier, ${ }^{13} \mathrm{j}$ 'avais souligné que le premier psautier davidique Ps 3-41, constituait une réaffirmation de la dynastie, particulièrement le Ps 18 , en inclusion avec le cinquième livre du Psautier, Ps 107-150, voir particulièrement le Ps 110. Dans le cas du Ps 18, le titre de 18,1 , répond aux titres pessimistes se référant à la persécution de David dans les Ps 52-60, particulièrement les titres longs. Ps 18,1 mentionne tous les ennemis et spécialement Saül. La réaffirmation messianique est par ailleurs clairement exprimée en Ps 18,51: «Il multiplie pour son roi les délivrances et montre de l'amour pour son oint, pour David et sa descendance (ולזרעו) à jamais»». A la suite du congrès de Berlin, j'ai considéré que la réaffirmation messianique du premier psautier davidique, correspondait également à une réaffirmation du pauvre marginal, voir mon article de la $Z A W .{ }^{15}$ Que cette réaffirmation prenne en compte le rôle de l'influence de Pr 30,1-14 sur le premier psautier davidique est évident, Ps 18,31: «Dieu, sa voie est sans reproche et la parole de Yahvé (צמרת יהוה) est éprouvée (צרופה). Il est, lui le bouclier (מגן) de quiconque s'abrite (החסים) en lui», reprend Pr 30,5: «Toute parole de Dieu (מרת יהוה) (מרום) (מרוה) (מרוה) (כל אמרת est éprouvée (צרופה), il est un bouclier (מגן) pour qui s'abrite (לחסים) en lui». La mention de Yahvé en Ps 18,31, est liée à la réaffirmation messianique davidique, David ayant fait monter l'arche de Yahvé à Jérusalem voir Ps $132^{16}$; 1 Ch 15-16. Dans la période d'incertitude quant à l'avenir de la dynastie, on a pu préférer אלהים ou אל יהוה pour éviter de mentionner, et donc la translation de l'arche par David. C'est le cas du psautier élohiste Ps 42-83, qui exprime les incertitudes quant à l'avenir de la dynastie suite à la chute de Jérusalem et à l'exil, voir au commencement du retour de l'exil et ses désordres sociaux. Le texte de

12 Jean-Luc Vesco, Le Psautier de David I, 63-64: «Le Ps 1, on l'a vu opposait le juste et les impies. Le Ps 2 oppose le roi-messie de YHWH et les rois des nations... Au juste qui "murmure" la tôrah (Ps 1,2), s'opposent les païens qui "murmurent" la vanité (Ps $2,1) \ldots »$.

13 Gosse, L'espérance messianique davidique.

14 Voir זר en Ps 89,5.30.37, le Ps 89 constatant la fin de la dynastie.

15 ZAW 130 (2018): 586-601.

16 Frank-Lothar Hossfeld and Erich Zenger, Psalms 3. A Commentary on Psalms 101150 (Hermeneia; trans. Linda M. Maloney; Minneapolis, MN: Fortress, 2011), 457, souligne le rapport du Ps 132 avec les textes sur l'arche d'alliance dont Nb 10,35-36, et l'importance rédactionnelle de ce psaume dans la Bible. 
Ps 18,32: «Qui donc est Dieu (אלוה), hors Yahvé ? Qui est rocher, sinon notre Dieu?», inverse la question de Pr 30,9: «de crainte que, comblé je me détourne et ne dise: "Qui est Yahvé ?"». Cette inversion de la question correspond exactement à la réaffirmation de Yahvé, et donc de David et sa descendance par référence au transfert de l'arche de Yahvé à Jérusalem par David. J'ai de plus montré que Ps 18,31-32, correspondait à une annonce du plan du Ps $19 .{ }^{17}$

\section{LA RÉFÉRENCE À L'ARCHE D'ALLIANCE DANS LE PSAUME 68 ET SON INFLUENCE SUR LE PREMIER PSAUTIER DA VIDIQUE}

Nous venons de voir l'importance de la référence à l'arche d'alliance de Yahvé, quant à la réaffirmation de la dynastie davidique dans le Psautier. L'arche est évoquée en Ps 68,2: «Que Dieu se dresse (יקום), et ses ennemis se dispersent, et ses adversaires fuient devant sa face», avec référence à $\mathrm{Nb}$ 10,35: «Quand l'arche partait, Moïse disait: "Lève-toi (קוםה), Yahvé, que tes ennemis se dispersent, que ceux qui te haïssent fuient devant toi!"’ Dans le Ps 68, les pauvres sont pris en compte, à commencer par la pauvreté liée aux incidents de la vie avec la mention en 68,6, des orphelins: יתומים; et des veuves: אלמנות. Mais sont également mentionnés en 68,7, les isolés: אידים יחים : אלמנת: et les captifs: On trouve également la mention du pauvre עני 68,11.

C'est dans cette perspective qu'il faut lire Ps 12,6. «A cause du pauvre (עניים) qu'on dépouille, du malheureux (אביונים) qui gémit, maintenant je me dresse (אקום), déclare Yahvé: j'assurerai le salut à ceux qui y aspirent». On peut déjà mentionner l'élargissement du vocabulaire du pauvre avec l'usage du terme אביון, en parallèle de עני.

Les liens entre le livre des Nombres et la réaffirmation messianique dans le Psautier, ne sont pas surprenants, en référence à l'arche de Yahvé. Le psautier élohiste, Ps 42-83, soit 42 psaumes débutant au Ps 42, traite également des incertitudes quant à l'avenir de la dynastie. Les Ps $84^{18}$ - 89 , constatent la disparition de la dynastie. Les Ps 90-106 proposent des alternatives, particulièrement avec le rôle joué par Moïse, mentionné dès le titre de Ps 90,1. Le premier livre Ps 1-41 et le cinquième Ps 107-150, participent de la réaffirmation messianique davidique. Or la réaffirmation messianique apparaît également en $\mathrm{Nb} 24,17$, dans les oracles de Balaam de $\mathrm{Nb} 22-24 .{ }^{19}$ Cette

17 Bernard Gosse, «Le Ps 19 prolongement du Ps 18 : Baal, El, Yahvé, le triple parallélisme synonymique, l'influence du livre des Proverbes et la Loi et David», ZAW 129 (2017): 568-582.

18 Le משיח de Ps 84,10, est le prêtre, en substitution du messie davidique de Ps 89,3952. Ce terme n'est jamais utilisé dans le Psautier élohiste, ce qui entretient l'incertitude. Marvin E. Tate, Psalms 51-100 (WBC 20; Dallas, TX: Word, 1990), 360: «The ancestors of Israel are referred to as "my anointed ones" in Ps 105:15».

19 Bernard Gosse, «Balaam et la dynastie davidique», BN 169 (2016): 129-139. 
réaffirmation messianique survient après 42 sacrifices en vue de maudire, qui débouchent finalement sur une bénédiction, particulièrement de la dynastie. En Egypte, le nombre 42 joue également un rôle important dans, «Le Livre Des Morts», lors du jugement des défunts, avec 42 dieux juges secondaires assesseurs du jugement opéré par Maat et 42 pétitions d'innocences pour gagner la confiance des dieux. Le jugement pouvait être défavorable ou favorable, bénédiction ou malédiction. En Egypte il y eu également à une période 42 nomes, ou circonscriptions territoriales. On interprétait comme une malédiction les disputes continuelles. Mais quand l'union se faisait, la malédiction se transformait en bénédiction. ${ }^{20}$

La réaffirmation messianique, en référence à l'arche d'alliance, que David a fait monter à Jérusalem apparaît encore avec l'usage du verbe קום: Ps 3,8; 7,7; 9,$20 ; 10,12 ; 17,13 ; 35,2 ; 44,27 ; 74,22 ; 82,8 ; 132,8$. En Ps 132,8 , il s'agit justement d'une référence au transfert de l'arche par David. En Ps 3,8 nous relevons קומה יהוה, avec la référence aux oppresseurs, qui se lèvent (קמים). En Ps 9,19-20, la référence à la délivrance du pauvre est encore plus explicite: «(19) Car le pauvre (אביון) n'est pas oublié jusqu'à la fin, l'espoir des malheureux (ענוים) ne périt pas à jamais. (20) Dresse-toi (קומה), Yahvé (יהוה), que l'homme ne triomphe, qu'ils soient jugés, les païens, devant ta face!» Il en est de même en Ps 10,12: «Dresse-toi (יהוה), (קומה), Yahvé Oieu, lève ta main, n'oublie pas les malheureux (ענוים)». Le terme ענים était déjà présent en Ps 68,11. Mais dans le premier livre du Psautier, d'autres termes synonymes ou plus explicites apparaissent, alors que le vocabulaire traditionnel de la pauvreté, avec la mention de la veuve et de l'orphelin, disparaît presque complétement. Le קומה יהוה de Ps 17,13, invite Yahvé à intervenir face aux arrogants enfermés dans leur graisse (v. 10), comparés à des lions qui cherchent leurs proies. Cela correspond à une dénonciation non seulement de l'injustice sociale, mais encore de la violence. Le קומה de 35,2, concerne égalent Yahvé, la ruse est dénoncée en 35,7, et en 35,10 il est question de délivrer le pauvre עביון et עי עי. Nous allons étudier maintenant le vocabulaire du pauvre dans le premier livre du Psautier.

\section{E LE VOCABULAIRE DU PAUVRE DANS LE PREMIER PSAUTIER DA VIDIQUE PSAUMES 3-41}

Dans les Ps 3-41, il faut relever que le «juste» est souvent identifié au pauvre exploité au retour de 1'exil. Les termes ענו et עני, constituent une caractéristique de la présentation du pauvre dans le premier psautier davidique, avec ענרי Ps

20 Bernard Gosse, «The 42 Generations of the Genealogy of Jesus in Matt 1:1-17, and the Symbolism of number 42, Curse or Blessing, in the Bible and in Egypt», Studia Biblica Slovaca 10/2 (2018): 142-151.

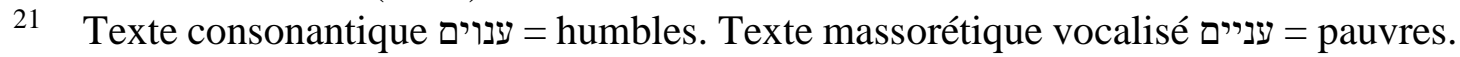
עes ענוים sont une spiritualisation des ענוים 
$\left(9,13^{22} .19^{23}\right) ; 10,2.9 .\left(12^{24}\right) ; 12,6 ; 14,6 ; 18,28 ; 22,25 ; 25,16 ; 34,7 ; 35,10 ; 37,14$; 40,18; voir: $(9,13.19) ; 10,(12) .17 ; 22,27 ; 25,9 ; 34,3 ; 37,11$. On voit que ענו apparaît soit comme une alternative de lecture de עני, soit dans le voisinage

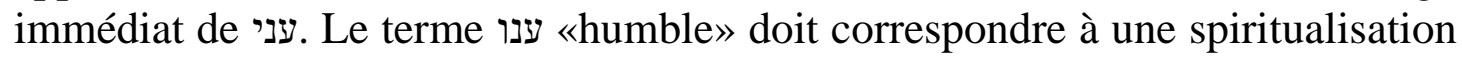
du terme עני ענ, comme Phil Botha l'a noté. ${ }^{25}$ Quant au terme complété par le parallèle אביון, en: Ps 9,19; 12,6; 35,10; 37,14; 40,18. La pauvreté est encore qualifiée par «isolé» יחירון: Ps 22,21; 25,16; 35,17 (68,7, seul autre emploi du Psautier) et «oppressé» 7ד: Ps 9,10; 10,18 (74,21, seul autre emploi du Psautier ${ }^{26}$. La pauvreté ainsi prise en compte apparaît différente de celle traditionnelle, liée aux malheurs de la vie avec dans le Psautier: «veuve» אלמנה: Ps 68,6; 78,64; 94,6; 109,9; 146,9 et «orphelin» יתום: Ps 10,14.18; 68,6; 82,3; 94,$6 ; 109,9.12 ; 146,9$.

La prise en compte du parallélisme אביון / עני, apparaît encore dans le Psautier en référence aux relectures davidiques du Psautier où à la situation sociale postérieure à la destruction du temple, Ps 70,6 = 40,18 (titres davidiques); $72,4.12$ qui parle du roi de l'avenir identifié à Salomon (fin du second psautier davidique), et en Ps 74,21, où l'oppression sociale mentionnée en Ps 74,20 apparaît en relation avec la situation sociale postérieure à la destruction du temple selon le début du psaume. En Ps 86,1, il s'agit d'une prière davidique ultérieure insérée dans des psaumes avec titres de chantres lévitiques. Ps 109,16.22, correspond à un psaume davidique, et de même en Ps 140,13. Il s'agit d'une réaffirmation des droits des pauvres et malheureux en lien avec la réaffirmation messianique. Au Ps 109,22: «Pauvre et malheureux (ואביון / עני) que je suis, mon cœur est blessé au fond de moi», il est répondu en 109,31: «car il se tient à la droite (לימין) du pauvre (אביון) pour sauver de ses juges son âme», avec en Ps 110,1: «De David Psaume. Oracle de Yahvé à mon Seigneur: "Siège à ma droite (לימיני), tant que j'aie fait de tes ennemis l'escabeau de tes pieds".», et en Ps 140,13: «Je sais que Yahvé fera droit aux malheureux (עני), qu'il fera justice aux pauvres (אביונים)».

Dans le dernier psaume du premier psautier davidique apparaît pour la première fois en Ps 41,2, pour désigner le pauvre, le terme דל Ce terme présent 14 fois dans les Proverbes, se rencontre en Ps 72,13 (en même temps que עניון et אביון), avec l'espoir que le roi promis fera justice. En Ps 82,3.4 (avec אביון , עני et יתום), il s'agit d'un rappel aux juges pour qu'ils fassent respecter le droit. En Ps

\footnotetext{
22 עניים vocalisé comme ענוים עueco.

23 ענוים vocalisé comme ענים viים viים viים

24 עניים vocalisé comme ענוים viים

25 Phil Botha, «The Social setting and strategy of Psalm 34», OTE 10 (1997): 187: «And yet... the material and sociological meaning of 'humble' (ענוים) never disappeared when the religious-ethical connotation grew in importance. These people did not have a lavish style of living since the majority of them was poor».

26 Seul autre emploi biblique $\operatorname{Pr} 26,28$, pour désigner les victimes du mensonge.
} 
113,7, le אביון en parallèle de doit s'asseoir au rang des princes du peuple de Yahvé. D'où l'importance du pauvre (דל) dont il faut prendre soin en Ps 41,2, en conclusion du premier livre du Psautier.

\section{F LA QUESTION SOCIALE ET LE PAUVRE DANS LE PREMIER PSAUTIER DAVIDIQUE}

En Ps 4,3: «Fils d'homme (בני איש), jusqu'où irez-vous dans l'insulte à ma gloire (כבודי), dans l'amour du néant et la course au mensonge?», la gloire est celle du psalmiste comme en Ps 7,6 ou pour l'homme créé en 8,6. La remise en cause de cette gloire doit correspondre à une atteinte à sa dignité, ${ }^{27}$ de la part des gens גם :בני איש àches comme le laisse supposer l'expression אדם correspondent aux riches et les בני איש Les בני אדם גם בני איש יחד עשיר ואביון בני aux pauvres, selon un chiasme. ${ }^{28}$ La même image apparaît en Ps 62,10, et le contexte laisse entendre que l'enrichissement des בני איש, n'est qu'illusion. ${ }^{29}$

Le texte de Ps 5,6-7: «6 non, les arrogants ne tiennent pas devant ton regard. Tu hais tous les malfaisants (פעלי און), 7 tu fais périr les menteurs; l'homme de sang (דמים) et de fraude (ומרמה), Yahvé le déteste», est conforme à Pr 10,29: «La voie de Yahvé est un rempart pour l'homme honnête, pour les malfaisants (לפעלי און), une ruine ». ${ }^{30} \mathrm{La}$ dénonciation de la fraude מרמה, est conforme à Pr 11,1a: «La balance fausse est une abomination pour Yahvé (מרון מאזני מרםה תועבת (מאת

En Ps 6,8, sont mentionnés les «oppresseurs» צוררי, qui font le mal selon 6,9: (עמון en Ps 7,7, et en 7,15 celui qui engendre le mal (עוררי (עמל) (עון), la peine et le mécompte (שקר). Celui qui prépare des traquenards $(7,16)$, verra sa violence (חמסו) (7,17), se retourner contre lui. ${ }^{33}$ Cette perspective est conforme à Pr 26,27.

27 Frank-Lothar Hossfeld and Erich Zenger, Die Psalmen I. Psalm 1-50 (NEB 29; Würzburg: Echter, 1993), 59.

28 Kraus, Psalms 1-59, 481.

29 Nancy deClaissé-Walford, Rolf A. Jacobson and Beth LaNeel Tanner. The Book of Psalms (NICOT; Grand Rapids, MI: Eerdmans, 2014), 517, laisse la question en suspens. Mais voir Louis Jacquet, Les Psaumes et le coeur de l'homme: étude textuelle, littéraire et doctrinale. Volume 2, Psaumes 42 à 100 (Gembloux: Duculot, 1977), 284 et Hans-Joachim Kraus, Psalms 60-150: A Commentary (CC; trans. Hilton C. Oswald; Minneapolis, MN: Augsburg, 1989), 15.

30 Gosse, L'influence du livre des Proverbes, 59.

31 En Is 59,3, le terme se rapporte aux désillusions du retour de l'exil, dans la continuité d'Is 58 .

32 Voir également le livre de Jérémie. Samuel Terrien, The Psalms: Strophic Structure and Theological Commentary (ECC; Grand Rapids, MI: Eerdmans, 2003), 115.

33 deClaissé-Walford et al., Book of Psalms, 117, soulignent que le méchant est à la fois victime du jugement de Dieu et de son propre comportement. 
Au sujet du pauvre dans les Ps 9-10, ${ }^{34}$ en plus des termes עביון עי, en note 1'“opprimé" דך en 9,10; 10,18 et le verbe דכה en 10,10. Le texte de Ps 9,19: «Car le pauvre (אביון) n'est pas oublié jusqu'à la fin, l'espoir (תקות) des malheureux (ענוים) ne périt pas à jamais», correspond à Pr 23,17-18: « ${ }^{17}$ Que ton cœur n'envie pas les pécheurs, mais dans la crainte de Yahvé qu'il reste tout le jour. ${ }^{18}$ Car il existe un avenir et ton espérance (ותקותך) ne sera pas anéantie». La violence contre le pauvre est encore dénoncée en Ps 10,2: «Sous 1'orgueil de l'impie (רשע) le malheureux (עני) est pourchassé, il est pris aux ruses que l'autre

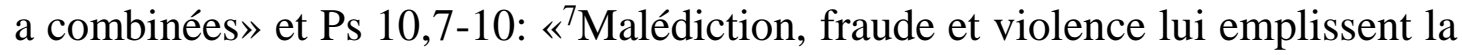
bouche, sous sa langue peine et méfait; ${ }^{8}$ il est assis à l'affût dans les roseaux, sous les couverts il massacre l'innocent. Des yeux il épie le misérable, 9̀à l'affût, bien couvert, comme un lion dans son fourré, à l'affût pour ravir le malheureux (עני), il ravit le malheureux (עני) en le traînant dans son filet. ${ }^{10}$ Il épie, s'accroupit, se tapit, le misérable (חלכאים) tombe en son pouvoir». ${ }^{36}$ Ce passage correspond à Pr 1,16-18 et en ce qui concerne l'avidité בצע, en Ps 10,3, voir Pr 1,19.

Le texte de Ps 12,6, répond à Pr 30,14, comme nous l'avons noté plus haut. ${ }^{37}$ Le Ps 13 traite également de l'oppression avec en Ps 13,5b: יגילו כי אמוט צרי. Les dénonciations des exactions contre les pauvres en Ps 14,4: «Ne le savent-ils pas, tous les malfaisants (פעלי און)? Ils dévorent mon peuple (אכלי עמי), voilà le pain qu'ils mangent, ils n'invoquent pas Yahvé» et 14,6: «vous bafouez la révolte du pauvre (עני), mais Yahvé est son abri», correspondent à l'impiété des riches. Le אין אלהים de 14,1 correspond au double לא יתי אל (לאלים de Pr 30,1. On peut également en rapprocher le «dévore les pauvres (לאכל עניים)》, de Pr 30,14.

Le passage de Ps 15,5: «ne prête pas son argent à intérêt», se réfère à un emprunt nécessaire à la survie. ${ }^{38}$ Le texte de Ps 17,10: «Ils sont enfermés dans leur graisse, ${ }^{39}$ ils parlent l'arrogance à la bouche», dénonce l'injustice sociale qui a pour conséquence le surpoids des exploiteurs. Le texte de Ps 18,28: «toi qui sauves le peuple des humbles (עני), et rabaisses les yeux (ועינים) hautains», reprend le vocabulaire de $\operatorname{Pr}$ 30,13-14, de même que Ps 18,31-32 s'appuie sur Pr 30,5.9. La violence est mentionnée en Ps 21,12: «S’ils dirigent contre toi le malheur, s'ils mûrissent un plan: ils ne pourront rien». Mais la rébellion contre le messie, identifié au pauvre, est vouée à l'échec selon Ps 2,4-12.

On peut lire en Ps 22:21-22: «"1 délivre de l'épée mon âme, de la patte du chien, mon isolement (יחידתי); ${ }^{22}$ sauve-moi de la gueule du lion, de la corne du

34 Ces deux psaumes constituent une seule continuité alphabétique.

35 תקוה: Ps 9,19; 62,6; 71,5, toujours pour parler de l'espérance de la victime.

36 deClaissé-Walford et al., Book of Psalms, 141, soulignent la violence suggérée par les images poétiques.

37 Pour Ps 12,3 voir Is 59,3-4.

38 Lév 25,35-38.

39 Vesco, Le Psautier de David I, 192: «La graisse paralyse le cœur, elle endurcit et rend inintelligent (Is 6,10)». 
taureau. Tu m'as répondu (עניתני)》. La réponse divine se comprend bien en fonction de l'action de grâce qui suit. Mais s'il y a une racine עני = répondre, il existe une autre racine ענה = être affligé, qui correspond au texte qui précéde. On peut comprendre que celui auquel Yahvé répond, c'est celui qui est affligé. Ce jeu de mots correspond tout à fait à la réaffirmation du pauvre en même temps que la réaffirmation messianique davidique, les titres davidiques identifiant David aux pauvres des psaumes. L'isolement par la persécution, apparaît comme une caractéristique du retour de l'exil.

L'isolement et la pauvreté qui en découle sont mentionnés conjointement

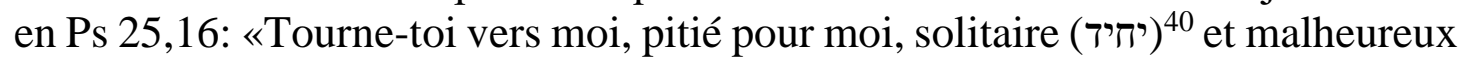
(ועני) que je suis». L'oppression apparaît en Ps 27,12: «ne me livre pas à l'appétit de mes oppresseurs (צרי): contre moi se sont dressés (קמו) de faux témoins qui soufflent la violence». Le psaume souligne l'isolement du psalmiste. ${ }^{41}$

La malhonnêteté est mentionnée en Ps 28,3-4: « ${ }^{3} \mathrm{Ne}$ me traîne pas avec les impies, avec les malfaisants, qui parlent de paix à leur prochain, et le mal est dans leur cœur. ${ }^{4}$ Donne-leur, selon leurs œuvres et la malice de leurs actes, selon l'ouvrage de leurs mains donne-leur, paie-les de leur salaire». ${ }^{42}$ Ces comportements sont justifiés par l'arrogance selon Ps 31,19: «silence aux lèvres de mensonge qui parlent du juste insolemment avec arrogance et mépris!» 43

Le salut du pauvre est mentionné en 34,7: «Un pauvre (עני) a crié, Yahvé écoute, et de toutes ses angoisses (צרותיו) il le sauve», ${ }^{44}$ face aux oppresseurs comparés à des fauves en 34,11. Yahvé s'oppose aux malfaisants (בעשי רע), en 34,17. Ce point correspond à $\operatorname{Pr} 1,18 .{ }^{45} \mathrm{~A}$ la ruse mentionnée en 35,7 , la violence en $35,10 \mathrm{~b}$, et la comparaison des ennemis à des lions, d'où la conséquence de l'isolement en Ps 35,17: «Seigneur, combien de temps verras-tu cela ? Soustrais mon âme à leurs ravages, aux lionceaux mon isolement (יחידתי)》, il est répondu, par la promesse de l'échec en Pr 1,17-19. ${ }^{46}$ La violence de l'injustice est encore soulignée en Ps 37,14: «Les impies tirent l'épée, ils tendent l'arc, pour égorger l'homme droit, pour renverser le pauvre (עני) et le petit (אביון)».

40 יחיד 12 fois dans la Bible, dont trois fois en Gn 22,2.12.16.

41 deClaissé-Walford et al., Book of Psalms, 271: «The psalmist's relational isolation and danger...»

42 Vesco, Le Psautier de David I, 280, souligne que le «cœur» des impies est plein de mal alors que celui du psalmiste se confie à Dieu.

43 Terrien, Psalms, 289: «flooded him with calumnies for they assumed for themselves the authority to judge...»

44 Phil Botha, «Psalm 34 and the Ethics of the Editors of the Psalter», in Psalmody and Poetry in Old Testament Ethics (LHBOTS 572; ed. Dirk J. Human; London: T\&T Clark, 2012), 56-75.

45 deClaissé-Walford et al., Book of Psalms, 328.

46 Hossfeld and Zenger, Die Psalmen I. Psalm 1-50, 216, renvoient à Pr 1,17. 
Un nouveau terme pour désigner le pauvre apparaît en Ps 41,2a: «Heureux (אשרי) qui pense au pauvre (דל)». La conclusion du premier livre du Psautier insiste donc sur la nécessité de l'attention aux pauvres.

\section{G CONCLUSION}

L'insistance sur les pauvres exploités du retour de l'exil, dans le premier psautier davidique apparaît donc conforme à l'influence du livre des Proverbes sur le Psautier et plus spécialement $\operatorname{Pr} 30,1-14$. Ps 18,28 répond directement à $\operatorname{Pr} 30,13$ 14. La réaffirmation davidique dans le premier psautier davidique, particulièrement le Ps 18, en réponse aux titres alarmistes du second psautier davidique, se fait également dans la mouvance de $\operatorname{Pr} 30,1-14$. Etant donné l'attribution à David des psaumes traitant du pauvre dans le premier livre du Psautier, le pauvre apparaît également comme participant de la réaffirmation davidique. Cette réaffirmation conjointe du messie davidique et du pauvre, s'appuie sur la référence à l'arche d'alliance du Ps 68, qui renvoie au livre des Nombres, où apparaît également la réhabilitation davidique en référence au nombre 42, qui sert à mettre en scène les incertitudes de la dynastie dans le psautier Elohiste Ps 42-83. La réhabilitation de David est également celle de l'arche de Yahvé, que David a fait monter à Jérusalem. Le vocabulaire du pauvre, du premier psautier davidique, recoupe très peu celui traditionnel de la veuve et de l'orphelin. Il insiste au contraire sur les victimes de l'exploitation sociale et $\mathrm{du}$ brigandage, provoquant l'isolement des victimes, conformément aux dénonciations du livre d'Isaïe au retour de l'exil. Ainsi Phil Botha a eu raison de mettre en valeur mes travaux sur l'influence du livre des Proverbes sur les rédactions bibliques, particulièrement le Psautier, tout en insistant sur la question du pauvre marginal. En fait les deux approches n'en font qu'une.

\section{BIBLIOGRAPHIE}

Botha, Phil J. «The Social Setting and Strategy of Psalm 34». Old Testament Essays 10 (1997): 178-197.

Botha, Phil J. «'The honour of the righteous will be restored': Psalm 75 in its social context». Old Testament Essays 15 (2002): 320-334.

Botha, Phil J. «Pride and the Suffering of the Poor in the Persian Period: Psalm 12 in its Post-Exilic Context». Old Testament Essays 25 (2012): 40-56.

Botha, Phil J. «Psalm 34 and the Ethics of the Editors of the Psalter». Pages 56-75 in Psalmody and Poetry in Old Testament Ethics. Library of Hebrew Bible / Old Testament Studies 572. Edited by Dirk J. Human. London: T\&T Clark, 2013.

Bremer, Johannes. «Eine „Armenredaktion“ im 1. Davidpsalter? Impulse vor dem Hintergrund sozio-ökonomischer Entwicklungen». Pages 181-205 in Trägerkreise in den Psalmen. Bonner Biblische Beiträge 178. Edited by FrankLothar Hossfeld, Johannes Bremer and Till Magnus Steiner. Bonn: University Press / Göttingen: V\&R Unipress, 2017. https://doi.org/10.14220/9783737 $\underline{006118.181 .}$. 
deClaissé-Walford, Nancy, Rolf A. Jacobson, Beth LaNeel Tanner. The Book of Psalms. New International Commentary on the Old Testament. Grand Rapids, MI: Eerdmans, 2014.

Gosse, Bernard. «L'influence de Proverbes 30,1-14 sur les cantiques bibliques, à travers le Psautier». Zeitschrift für die Alttestamentliche Wissenschaft 119 (2007): 528538. https://doi.org/10.1515/ZAW.2007.037.

Gosse, Bernard. L'influence du livre des Proverbes sur les rédactions bibliques à l'époque Perse. Supplément à Transeuphratène 14. Paris: Gabalda, 2008.

Gosse, Bernard. L'espérance messianique davidique et la structuration du Psautier. Supplément à Transeuphratène 21. Pendé: Gabalda, 2015.

Gosse, Bernard. «Balaam et la dynastie davidique». Biblische Notizen 169 (2016): 129139.

Gosse, Bernard. «Le Ps 19 prolongement du Ps 18: Baal, El, Yahvé, le triple parallélisme synonymique, l'influence du livre des Proverbes et la Loi et David». Zeitschrift für die Alttestamentliche Wissenschaft 129 (2017): 568-582. https://doi .org/10.1515/zaw-2017-4005.

Gosse, Bernard. «La réaffirmation messianique du Ps 18 dans la perspective du salut du marginal au retour de l'exil». Zeitschrift für die Alttestamentliche Wissenschaft 130 (2018): 586-601. https://doi.org/10.1515/zaw-2018-4006.

Gosse, Bernard. «The 42 Generations of the Genealogy of Jesus in Matt 1:1-17, and the Symbolism of number 42, Curse or Blessing, in the Bible and in Egypt». Studia Biblica Slovaca 10 (2018): 142-151.

Gosse, Bernard. «David and Moses». Pages Xxx-xxx in Innovation in Persian Period Judah. Royal and Temple Ideology in its Near Eastern Setting. FAT II. Edited by Christine Mitchell and Katherine E. Smith. Tübingen: Mohr Siebeck, 2019.

Hossfeld, Frank-Lothar and Erich Zenger. Die Psalmen I. Psalm 1-50. Neue Echter Bibel 29. Würzburg: Echter, 1993.

Hossfeld, Frank-Lothar and Erich Zenger. Psalms 3. A Commentary on Psalms 101150. Hermeneia. Translated by Linda M. Maloney. Minneapolis, MN: Fortress, 2011.

Jacquet, Louis, Les Psaumes et le coeur de l'homme: étude textuelle, littéraire et doctrinale. Volume 2, Psaumes 42 à 100. Gembloux: Duculot, 1977.

Kraus, Hans-Joachim. Psalms 1-59: A Commentary. Continental Commentaries. Translated by Hilton C. Oswald. Minneapolis, MN: Augsburg, 1988.

Kraus, Hans-Joachim. Psalms 60-150: A Commentary. Continental Commentaries. Translated by Hilton C. Oswald. Minneapolis, MN: Augsburg, 1989.

Podechard, Emmanuel, Le Psautier. Traduction littérale et explication historique I, Psaumes 1-75. Lyon: Facultés catholiques, 1949.

Tate, Marvin E., Psalms 51-100. Word Biblical Commentary 20. Dallas, TX: Word, 1990.

Terrien, Samuel, The Psalms: Strophic Structure and Theological Commentary. Eerdmans Critical Commentary. Grand Rapids, MI: Eerdmans, 2003.

Vesco, Jean-Luc, Le Psautier de David traduit et commonté I. Lectio Divina 210. Paris: Cerf, 2006.

Dr Bernard Gosse, Antony, France, Email gosse.bernard.old@ orange.fr. 